\title{
The diagnostic value of circulating tumor cells and ctDNA for gene mutations in lung cancer
}

This article was published in the following Dove Medical Press journal: OncoTargets and Therapy

\author{
Mengyuan Lyu ${ }^{1,2, *}$ \\ Jian Zhou' ${ }^{1,3, *}$ \\ Kang Ning' \\ Binwu Ying ${ }^{2}$ \\ 'West China School of Medicine, \\ Sichuan University, Chengdu, \\ Sichuan, People's Republic of China; \\ ${ }^{2}$ Department of Laboratory Medicine, \\ West China Hospital, Sichuan \\ University, Chengdu, Sichuan, People's \\ Republic of China; ${ }^{3}$ Department \\ of Thoracic Surgery, West China \\ Hospital, Sichuan University, Chengdu, \\ Sichuan, People's Republic of China \\ *These authors contributed equally \\ to this work
}

Purpose: Detecting gene mutations by two competing biomarkers, circulating tumor cells (CTCs) and ctDNA has gradually paved a new diagnostic avenue for personalized medicine. We performed a comprehensive analysis to compare the diagnostic value of CTCs and ctDNA for gene mutations in lung cancer.

Methods: Publications were electronically searched in PubMed, Embase, and Web of Science as of July 2018. Pooled sensitivity, specificity, and AUC, each with a 95\% CI, were yielded. Subgroup analyses and sensitivity analyses were conducted. Quality assessment of included studies was also performed.

Results: From 4,283 candidate articles, we identified 47 articles with a total of 7,244 patients for qualitative review and meta-analysis. When detecting EGFR, the CTC and ctDNA groups had pooled sensitivity of $75.4 \%$ (95\% CI $0.683-0.817$ ) and $67.1 \%$ (95\% CI $0.647-0.695)$, respectively. When testing $K R A S$, pooled sensitivity was $38.7 \%$ (95\% CI $0.266-0.519)$ in the CTC group and $65.1 \%$ (95\% CI 0.558-0.736) in the ctDNA group. The diagnostic performance of ctDNA in testing $A L K$ and $B R A F$ was also evaluated. Heterogeneity among the 47 articles was acceptable.

Conclusion: ctDNA might be a more promising biomarker with equivalent performance to CTCs when detecting EGFR and its detailed subtypes, and superior diagnostic capacity when testing $K R A S$ and $A L K$. In addition, the diagnostic performance of ctDNA and CTCs depends on the detection methods greatly, and this warrants further studies to explore more sensitive methods. Keywords: lung cancer, circulating tumor cell, circulating tumor DNA, gene mutations

\section{Introduction}

Lung cancer has the highest incidence and mortality among cancer cases worldwide, with 2.1 million new lung cancer cases and 1.8 million lung cancer deaths in $2018 .{ }^{1}$ Accumulating evidence confirms that driven gene mutations play a critical role in the oncogenesis, personalized treatment, and prognosis assessment of lung cancer. ${ }^{2}$ Clearly, how to detect gene mutations more precisely is the cornerstone. Tissue biopsy is traditionally regarded as the gold standard for detecting gene mutations; however, invasiveness and high requirements for operation restrict its wide application. ${ }^{3}$

Currently, liquid biopsy focusing on the detection of ctDNA, circulating tumor DNA (ctDNA) and circulating tumor cell (CTCs) in the blood of cancer patients has shed new light on real-time monitoring of therapy, identifying drug resistance and surveillance of disease progression. ${ }^{4}$ ctDNA refers to the single- or double-stranded DNA released from TCs into the bloodstream, ${ }^{5}$ while CTCs are the cells released by primary tumors into peripheral blood. ${ }^{6}$ ctDNA and CTCs have paved new diagnostic avenues: collecting blood samples from cancer patients and isolating CTCs or extracting ctDNA, thereby obtaining a wealth of information on gene mutations,
Correspondence: Binwu Ying Department of Laboratory Medicine, West China Hospital, Sichuan University, 37 Guoxue Alley, Chengdu, Sichuan 61004I, People's Republic of China Tel $+86 \quad 18980601655$

Fax +86288542 275I

Email docbwy@I26.com 
cancer phenotype, tumor-mutation burden, and drug resistance. ${ }^{7}$ Noninvasiveness, predictability, and the same gene profile as primary tumors of ctDNA and CTCs have attracted enormous attention. However, which of the two competing biomarkers is better for detecting gene mutation in clinical practice is still a matter of debate. We undertook this metaanalysis to determine the diagnostic value of both ctDNA and CTCs in detecting different gene mutations in the blood of patients with lung cancer, including $E G F R, K R A S, A L K$, and $B R A F$, referred for tissue biopsy.

\section{Methods}

\section{Search strategy}

An electronic literature search of PubMed, Embase, and Web of Science as of July 2018 was performed by two independent reviewers. Search items were: lung, pulmonary AND cancer, carcinoma, tumor, neoplasm AND mutation AND serum, plasma, circulating. Some potential studies were manually searched from relevant reference lists. Any disagreements were discussed, and if necessary a third author would arbitrate.

\section{Inclusion and exclusion criteria}

Studies meeting all the following criteria were included: randomized controlled trials, cross-sectional studies, or cohort studies; focused on lung cancer patients; analyzed diagnostic value of CTCs or ctDNA for gene mutations; used tissue biopsy as the reference standard. Studies were excluded if they met one of the following criteria: reviews, letters, replies, case reports, conference abstracts, or animal experiments; articles not written in English; articles lacking essential information. Any disagreements were discussed.

\section{Quality assessment}

Two independent reviewers used RevMan version 5.3 to evaluate the quality of studies included based on the Quality Assessment of Diagnostic Accuracy Studies 2 tool. ${ }^{8}$ Questions, including patient selection, index test, reference standard, and flow and timing, would be judged as "yes", "unclear", or "no" for each of the included studies.

\section{Data extraction and management}

Two independent authors extracted data: basic data (first author, publication year, countries/regions, number of patients, age, sex, blood volume, isolation methods, extraction methods, detection methods, and others) and diagnostic data (true positive, false positive, true negative and false negative). Disagreements were resolved by consensus.

\section{Statistical analysis}

Meta-Disc version 1.4 was used to calculate pooled sensitivity, pooled specificity, AUC, positive-likelihood ratio and negative-likelihood ratio, each with a 95\% CI. Forest plots and a summary receiver-operating characteristic (sROC) curves were plotted to present the results visually. Both threshold effect and nonthreshold effect were assessed to find the potential source of heterogeneity. If the $P$-value of the Spearman correlation coefficient was $<0.05$, a threshold effect would exist. When the $P$-value of Cochran's $Q$ test was $<0.10$, a nonthreshold effect would be identified. Subgroup analyses were performed one subtypes of EGFR mutations, detection methods of liquid biopsy, and consistency of detection methods between liquid biopsy and tissue biopsy. Sensitivity analyses were also carried out to test the robustness of the main results by removing low-quality studies one by one. Quantitative evaluation of heterogeneity was evaluated by calculating $I^{2}$, in accordance with the Cochrane Collaboration. ${ }^{9}$

\section{Results Study characteristics}

A total of 47 of 4,283 studies were included in our analysis: nine ${ }^{10-18}$ in the CTC group and $42^{11,13,16,17,19-56}$ in the ctDNA group (four ${ }^{11,13,16,17}$ studies were in both groups; Figure 1). Detected gene mutations in lung cancer were mainly in $E G F R, K R A S, A L K$, and $B R A F$. The volume of blood samples varied from $5.9 \mathrm{~mL}$ to $20.0 \mathrm{~mL}$ in the CTC group, and $1.5 \mathrm{~mL}$ to $20 \mathrm{~mL}$ in the ctDNA group. Detection methods for gene mutations were mainly sequencing and PCR in either liquid biopsy or tissue biopsy. The main characteristics of the CTC group and ctDNA group are shown in Tables 1 and 2, respectively.

\section{Risk of bias}

In the CTC group, four studies were identified as low risk and one had unclear risk for the patient selection. Altogether, six publications were assessed as high risk and two had low risk on the index test. Low risk for reference standard was identified in all articles in this group. Four articles reported detailed information about flow and timing, assessed as low risk in this term. A total of four of nine, two of nine, and nine 


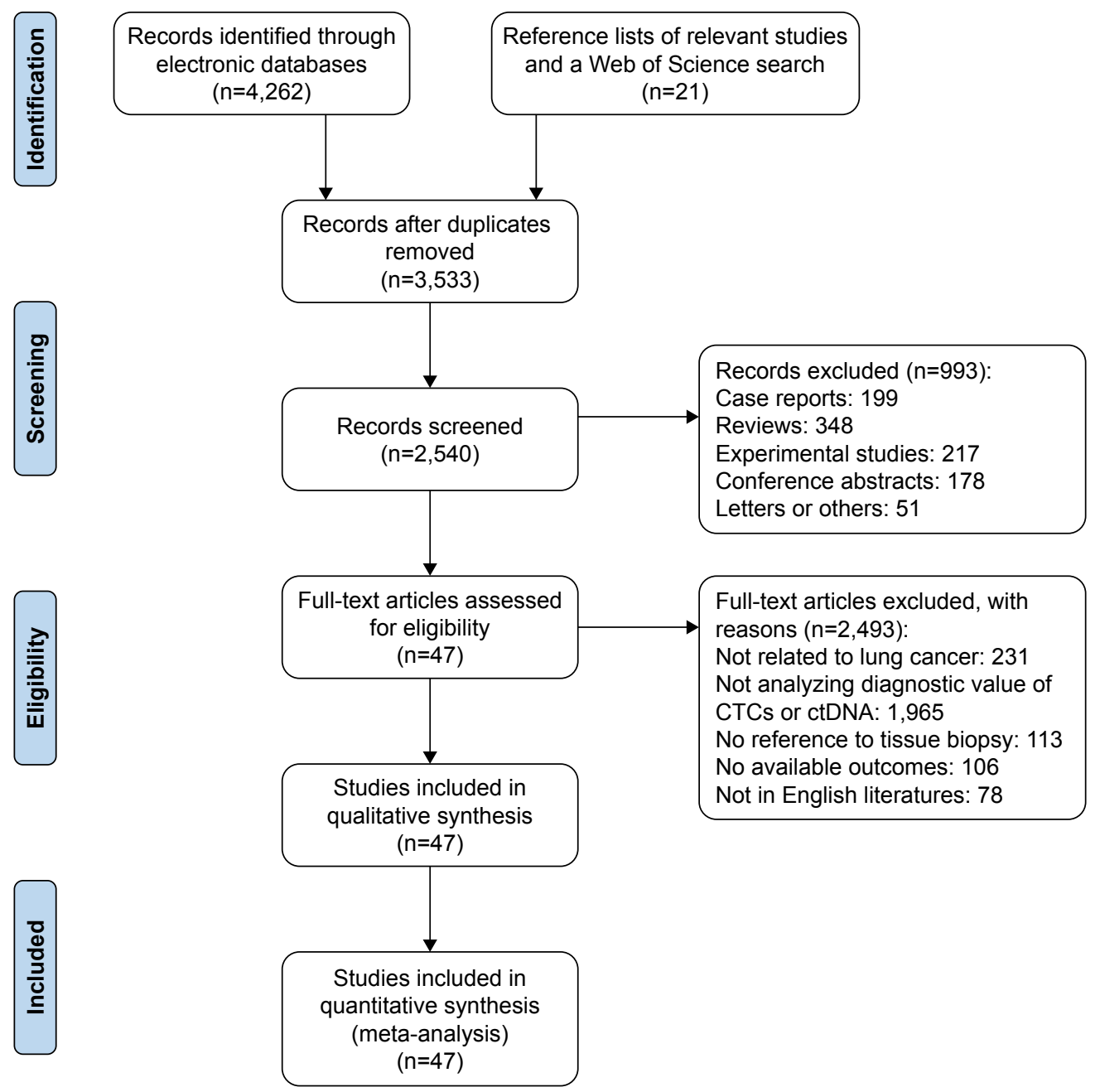

Figure I Flow diagram of article selection for this meta-analysis.

Abbreviations: CTCs, circulating tumor cells; ctDNA, circulating tumor DNA.

of nine articles had low concern regarding patient selection, index test, and reference standard, respectively. In the ctDNA group, 23 studies were assessed as low risk on patient selection, while two had unclear risk. There were 18 of 42 and 35 of 42 studies with low risk on the index test and reference standard, respectively. For flow and timing, 17 trials had low risk and the rest had high risk. A total of 23 of 42, 18 of 42, and 37 of 42 trials were identified as low concern for patient selection, index test, and reference standard, respectively. The risk of bias of the included studies is shown in Figure 2.

\section{Heterogeneity}

Using Spearman's correlation coefficient, we found that a threshold effect existed in the ctDNA group when detecting $A L K(r=1.000, P<0.001)$. Cochran's $Q$ indicated that a nonthreshold effect existed in the ctDNA group when testing $\operatorname{EGFR}\left(\chi^{2}=90.39, P<0.001\right), K R A S\left(\chi^{2}=22.73, P=0.007\right)$, and $B R A F\left(\chi^{2}=37.89, P<0.001\right)$. However, no nonthreshold effects were found in the CTC group regarding the detection of EGFR or KRAS. sROC curves for the CTC and ctDNA groups are shown in Figure 3.

\section{Diagnostic accuracy}

For EGFR, pooled sensitivity, specificity, and AUC were 75.4\% (95\% CI 0.683-0.817), 85.2\% (95\% CI 0.729-0.934), and $88.5 \%(95 \% \mathrm{CI} 0.778-0.993)$ in the CTC group and $67.1 \%$ (95\% CI 0.647-0.695), 96.1\% (95\% CI 0.954-0.968), and $83.91 \%$ (95\% CI 0.759-0.919) in ctDNA group, respectively. For $K R A S$, they were $38.7 \%$ (95\% CI $0.266-0.519), 92.1 \%$ (95\% CI 0.850-0.965), and 74.1\% (95\% CI 0.472-1.000) in the CTC group and $65.1 \%$ (95\% CI 0.558-0.736), 95.5\% (95\% CI 0.932-0.972), and 91.0\% (95\% CI 0.804-1.000) in the ctDNA group, respectively. For $B R A F$, they were $31.3 \%$ (95\% CI 0.141-0.532), 99.5\% (95\% CI 0.978-1.000), and 


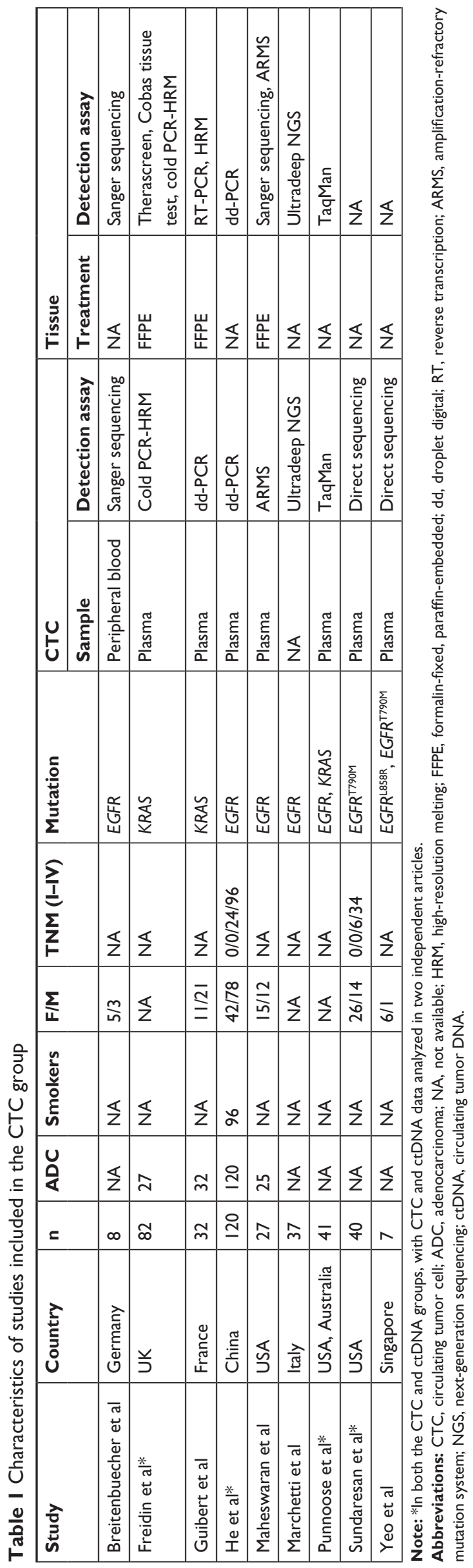

$87.7 \%$ (95\% CI 0-1.000) in the ctDNA group respectively. For $A L K$, only an sROC curve was plotted in ctDNA group, due to the threshold effect, and the ctDNA group had an AUC of $99.4 \%$ (95\% CI $0.953-1.000)$. Summary plots of the CTC and ctDNA groups are shown in Figures 4 and 5, respectively.

\section{Subgroup analyses}

Although we did not find a nonthreshold effect in the CTC group, we still performed subgroup analyses to identify potential influencing factors of CTCs when detecting different gene mutations.

\section{Subtypes of EGFR mutations}

Seven subtypes of EGFR mutations - Del19, L858R, T790M, L861Q, E20ins, G719X, and S768I - were taken into consideration. For Del19, three and 18 studies were included in the CTC group and ctDNA groups, respectively. The CTC group and ctDNA group had summary sensitivity of $75.9 \%$ (95\% CI $0.654-0.845)$ and $79.0 \%$ (95\% CI $0.767-0.812$ ), respectively. For L858R, the CTC group included four articles, while the ctDNA group had 20 studies. Pooled sensitivity was $62.2 \%(95 \%$ CI $0.501-0.732)$ in the CTC group and $76.7 \%$ (95\% CI $0.731-0.800)$ in the ctDNA group. For T790M, the CTC group had slightly higher sensitivity than the ctDNA group (63.3\% versus $61.2 \%)$. No significant findings were observed to explain the nonthreshold effect in the ctDNA group when detecting Del19, L858R, and T790M. However, a nonthreshold effect was not observed in ctDNA group when testing L861Q $\left(\chi^{2}=0.18, P=0.670\right)$, E20ins $\left(\chi^{2}=1.53, P=0.467\right)$, G719X $\left(\chi^{2}=0.09, P=0.765\right)$, or S768I $\left(\chi^{2}=0.27, P=0.606\right)$.

\section{Detection methods of CTCs or ctDNA}

The CTC group had higher sensitivity than the ctDNA group whether applying sequencing $(85.1 \%$ versus $75.6 \%$ ) or PCR (72.1\% versus $67.2 \%$ ) to detect $E G F R$. When sequencing was used to test $K R A S$, ctDNA showed excellent performance, with sensitivity of $66.9 \%$ (95\% CI $0.535-0.786$ ). When KRAS was detected by PCR, sensitivity was $30.8 \%$ (95\% CI $0.170-0.476)$ and $66.9 \%$ (95\% CI $0.535-0.786)$ in the CTC and ctDNA groups, respectively. When sequencing was employed to detect $B R A F$, sensitivity was $87.5 \%$ (95\% CI 0.473-0.997) in the ctDNA group. Heterogeneity brought by nonthreshold effects was not found in the ctDNA group $\left(\chi^{2}=0.086, P=0.872\right)$ when detecting $K R A S$ $\left(\chi^{2}=0.086, P=0.872\right)$ or $B R A F\left(\chi^{2}=0.62, P=0.892\right)$ by sequencing. 


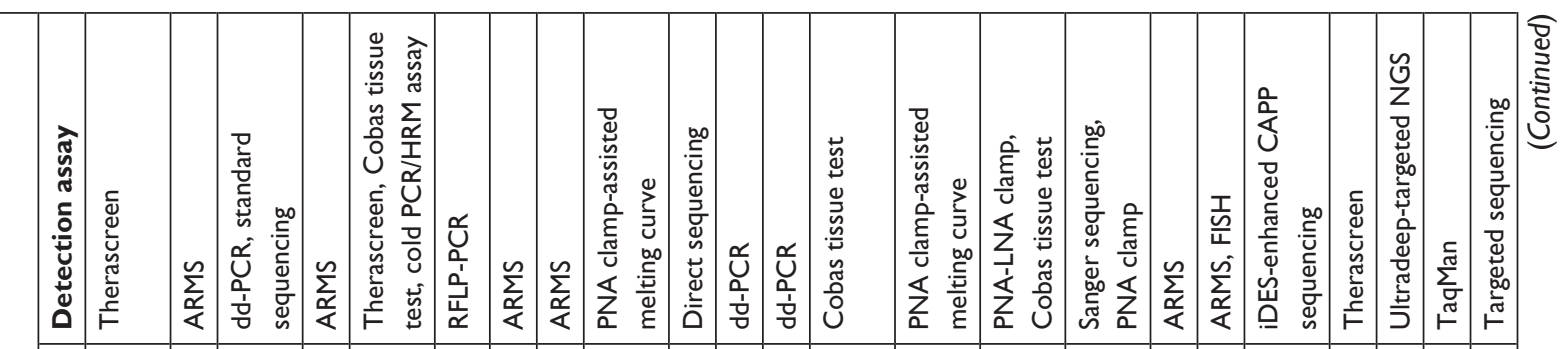

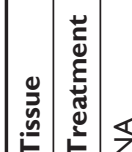

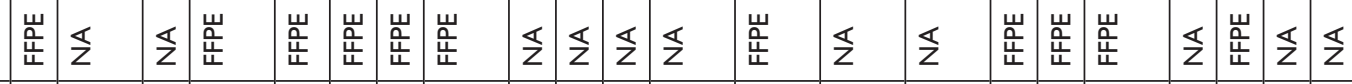

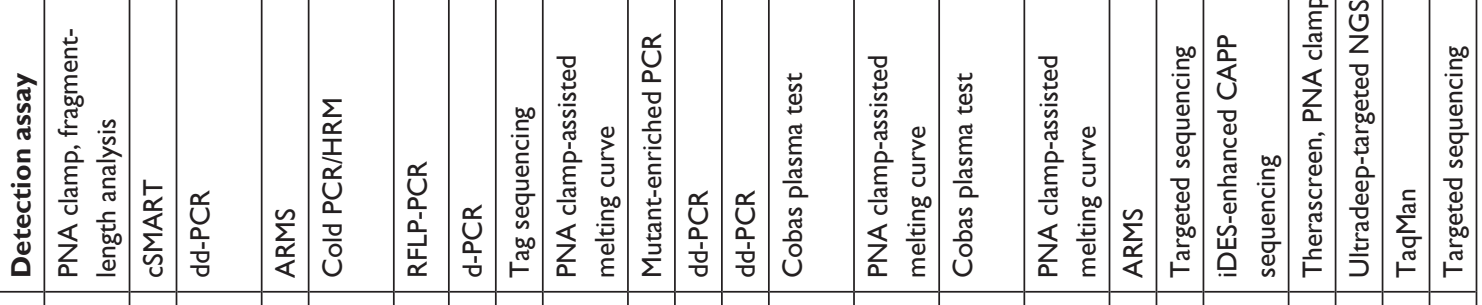

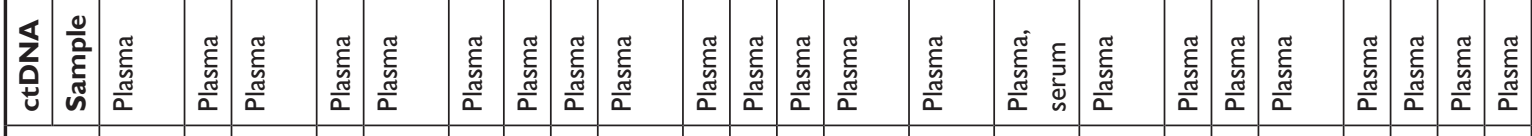

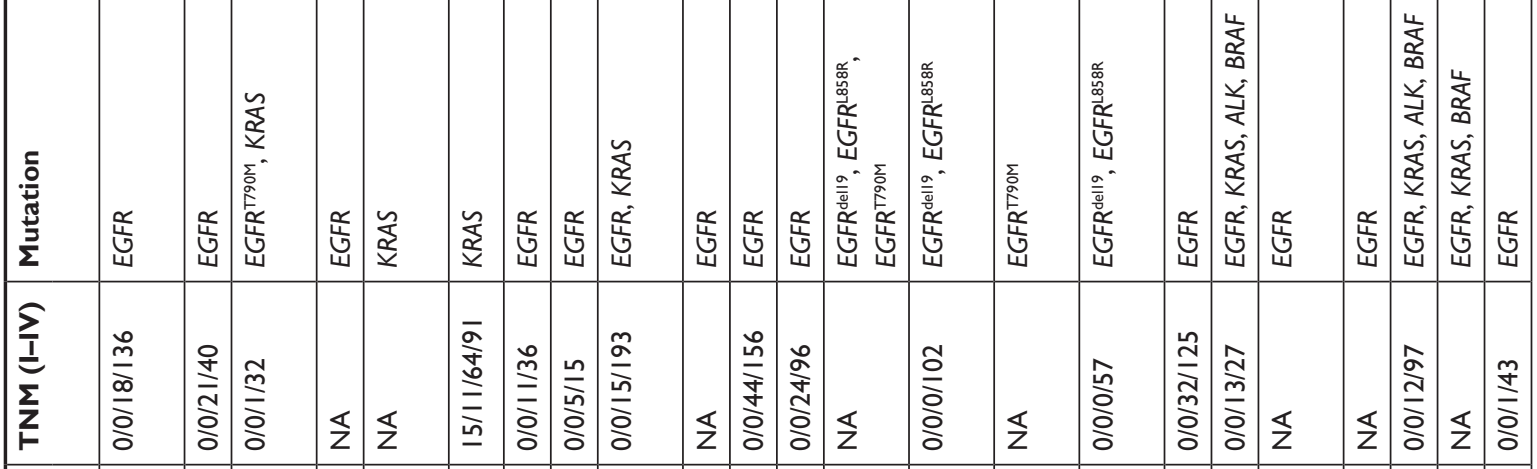

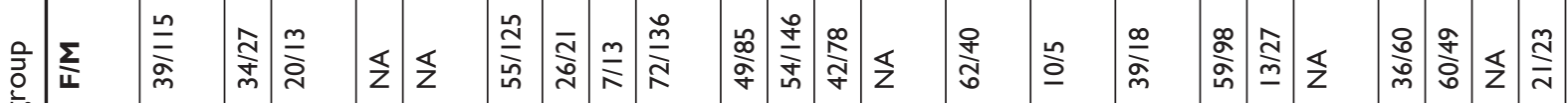

¿

\begin{tabular}{|c|c|c|c|c|c|c|c|c|c|c|c|c|c|c|c|c|c|c|c|c|c|c|}
\hline ñ & & $\bar{z}$ & $=$ & $\mathbb{z}$ & 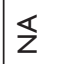 & $\stackrel{\sim}{\underline{N}}$ & $\mathbb{z}$ & $\infty$ & $\overline{\underline{m}}$ & ก) & 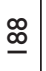 & 2 & ¿ & $\bar{m}$ & $r$ & $\underline{0}$ & P & $\bar{N}$ & $\leq$ & ț & $\stackrel{m}{n}$ & $\mathbb{Z}$ \\
\hline 过 & & $\stackrel{\infty}{\circ}$ & $\S$ & $\S$ & $\hat{N}$ & 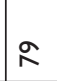 & f & ন & 声 & 흐 & ¿̊ & 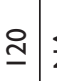 & $\S$ & 15 & $\S$ & in & $\underline{\hat{n}}$ & $\stackrel{\sim}{\sim}$ & ¿ & $\stackrel{\square}{\square}$ & $\S$ & $\S$ \\
\hline$=$ & $\stackrel{ \pm}{\underline{\underline{n}}}$ & $\overline{0}$ & m & $\begin{array}{l}0 \\
0 \\
0 \\
-1\end{array}$ & ळ & $\underline{\square}$ & f & ㄱ & $\stackrel{\text { : }}{\text { ¿े }}$ & $\stackrel{ \pm}{\underline{m}}$ & ¿̊. & さి & เก & $\underline{\widetilde{\delta}}$ & $\mathrm{H}$ & & 뜨 & q & 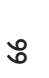 & ஃ & ô & $\bar{\sigma}$ \\
\hline 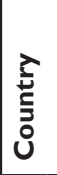 & 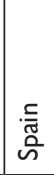 & 胥 & 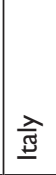 & 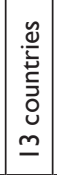 & 兰 & 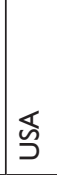 & 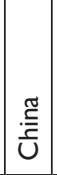 & 竞 & 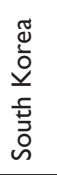 & \begin{tabular}{|l|} 
妾 \\
$\bar{U}$
\end{tabular} & 昙 & : & 兰 & 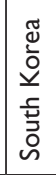 & 丞 & 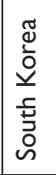 & 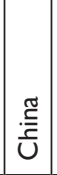 & 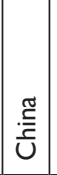 & $\overleftarrow{s}$ & $\begin{array}{l}\text { त्ञ } \\
\text { | }\end{array}$ & 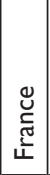 & 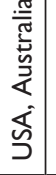 \\
\hline 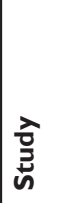 & 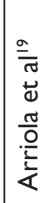 & 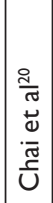 & 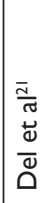 & 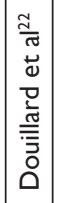 & 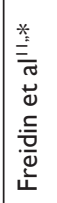 & 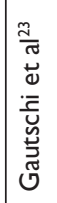 & 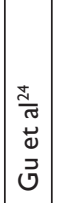 & $\begin{array}{l}\frac{a}{0} \\
\overrightarrow{0} \\
0 \\
\vec{J}\end{array}$ & 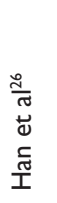 & \begin{tabular}{|l}
$\frac{\tilde{J}}{J}$ \\
$\tilde{J}$ \\
$\frac{\tilde{I}}{\mathrm{I}}$
\end{tabular} & $\begin{array}{l}\frac{\infty}{\pi} \\
\vec{J} \\
\frac{0}{I}\end{array}$ &  & $\begin{array}{l}\text { 旁 } \\
\underline{\underline{\underline{v}}}\end{array}$ & 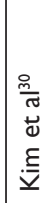 & 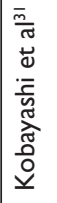 & 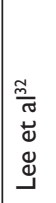 & 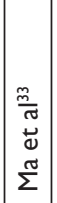 & 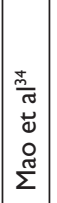 & $\frac{\stackrel{m}{\sigma}}{\sim}$ & 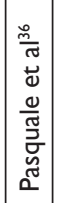 & 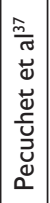 & 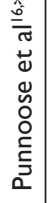 \\
\hline
\end{tabular}




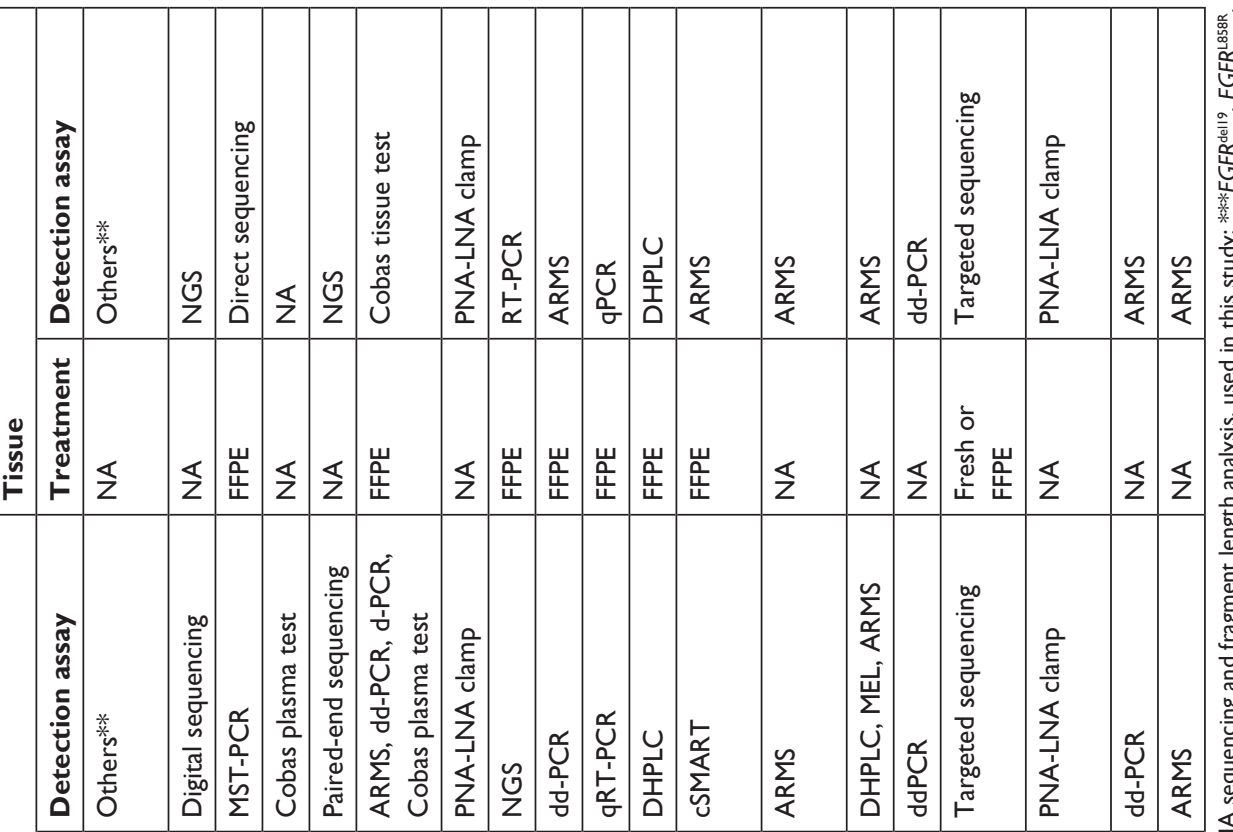

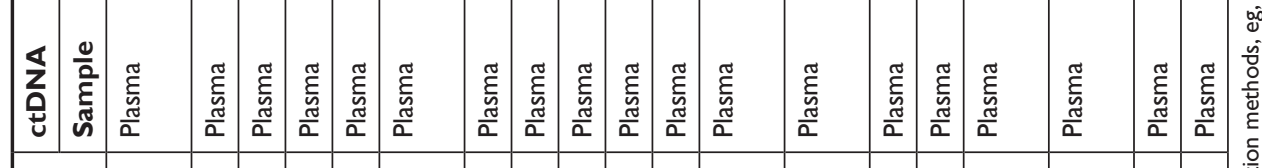

\begin{tabular}{|c|c|c|c|c|c|c|c|c|c|c|c|c|c|c|c|c|c|}
\hline 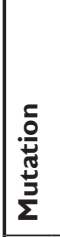 & & 总 & 总 & 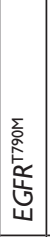 & 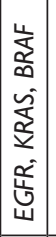 & 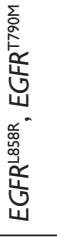 & 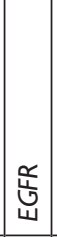 & $\begin{array}{l}\text { 总 } \\
\text { 出 }\end{array}$ & 胥 & 恙 & 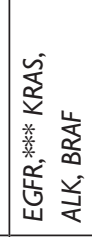 & 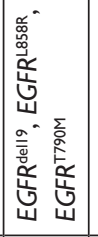 & 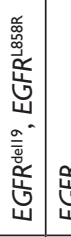 & 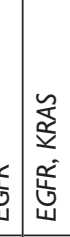 &  & 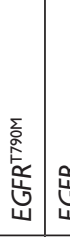 & 迢 \\
\hline$=$ & z & $\Sigma$ & $\S$ & 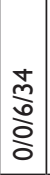 &  & $\Sigma$ & 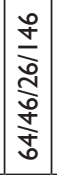 & 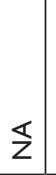 & 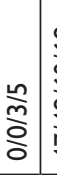 & 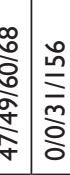 & 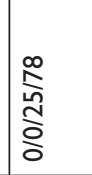 & 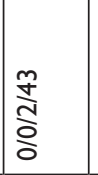 & 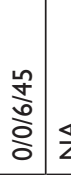 & 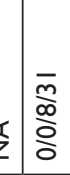 & 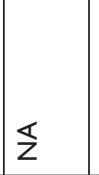 & 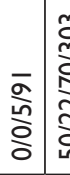 & 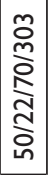 \\
\hline & & ○ & $\varangle$ & $\stackrel{+}{=}$ & 誉 & $\$$ & $\frac{\mathbf{o}}{\underline{\sigma}}$ & $\frac{\sigma}{\partial}$ & 䓵 & 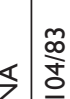 & $\stackrel{\infty}{4}$ & $\stackrel{\widetilde{N}}{\underset{N}{*}}$ & $\bar{m}$ & & & $\stackrel{+}{=}$ & 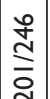 \\
\hline
\end{tabular}

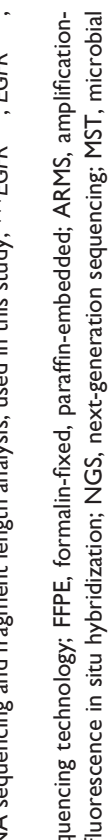

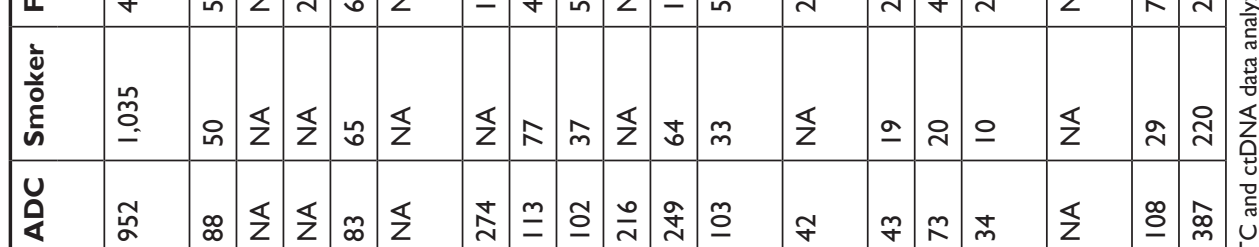







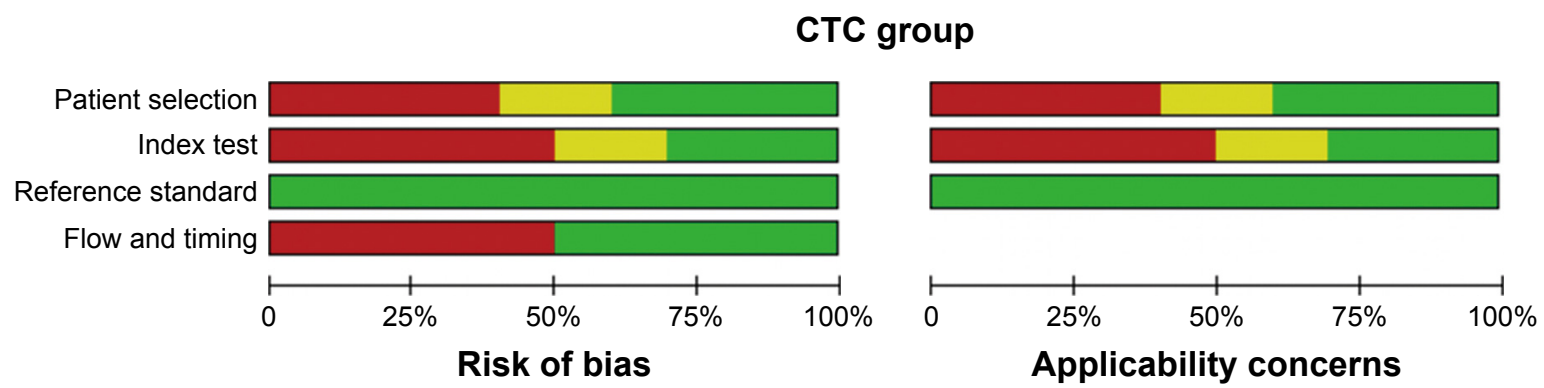

ctDNA group
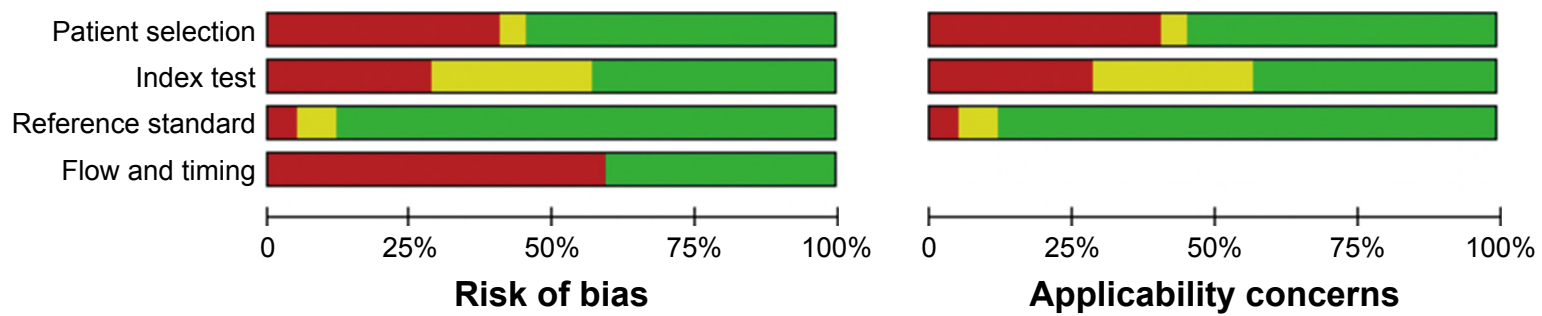

High $\square$ Unclear $\square$ Low

Figure 2 Risk of bias and applicability concerns in the CTC and ctDNA groups. Abbreviations: CTC, circulating tumor cell; ctDNA, circulating tumor DNA.

\section{Consistency of detection methods between liquid biopsy and tissue biopsy}

If the same method were employed for liquid biopsy and tissue biopsy to test gene mutations, this would be grouped in the consistent subgroup and otherwise the inconsistent subgroup. CTCs and ctDNA showed similar capacity for testing EGFR when using the consistent method with tissue biopsy. Higher sensitivity was identified when using inconsistent methods to detect ctDNA for KRAS $(81.5 \%, 95 \% \mathrm{CI}$ 0.673-0.914), as well as $B R A F(100 \%, 95 \%$ CI $0.398-1.000)$. Meanwhile, we did not find any nonthreshold effect in the ctDNA group when inconsistent methods were used for $B R A F$ analysis $\left(\chi^{2}=0.62, P=0.431\right)$. Results of subgroup analyses are shown in Table 3.

\section{Sensitivity analyses}

No significant results were identified in sensitivity analyses.

\section{Discussion}

We found that ctDNA and CTCs had similar performance when detecting $E G F R$ and its detailed subtypes. However, ctDNA showed great strength for detecting KRAS and $A L K$. Subgroup analyses indicated that detection method had a great impact on the diagnostic capacity of ctDNA and CTCs.

CTCs had slightly higher sensitivity than ctDNA when detecting $E G F R$, which has been supported by some researchers. ${ }^{14}$ This may partly be attributed to the low abundance of ctDNA in peripheral blood. Although the level of ctDNA in cancer individuals was much higher than normal, it still accounted for $<1 \%$ of cell-free DNA.${ }^{57} \mathrm{ctDNA}$ quantity is prone to be only one genome per $5 \mathrm{~mL}$ plasma in the early stage of cancer. ${ }^{58}$ Therefore, the effective capture of ctDNA is still technically challenging, though Punnoose et $a{ }^{16}$ held the opposite opinion that ctDNA might outperform CTCs for EGFR detection. Treatment status may explain this inconsistency to some extent. The proportion of patients receiving treatment in their trial was higher than that in ours, while therapy can decrease CTC counts more effectively and increase the difficulty of detection.

For $K R A S$, ctDNA showed excellent diagnostic ability. Shen et $\mathrm{a}^{59}$ conducted a meta-analysis and came to a different conclusion than us. They included two studies that we excluded during literature screening. ${ }^{60,61}$ One did not describe clearly whether they analyzed the value of CTCs or ctDNA ${ }^{60}$ while another extracted RNA from CTCs for detection. ${ }^{61}$ Great heterogeneity may exist between these two studies, which might have impacted the final results. Limited articles restricted us in analyzing the value of CTCs for $A L K$ detection. In the ctDNA group, pooled sensitivity and specificity were not yielded, because of a threshold effect, while sROC curves and AUC indicated the high value of ctDNA in testing $A L K$, in line with other investigators. ${ }^{62}$ For $B R A F$, the value of CTCs was not explored, due to limited studies. 



Figure 3 sROC curves for the CTC and ctDNA groups.

Abbreviations: CTC, circulating tumor cell; KRAS, kirsten rat sarcoma viral oncogene homolog; sROC, summary receiver operating characteristic curve; ctDNA, circulating tumor DNA; ALK, anaplastic lymphoma kinase; BRAF, B-Raf proto-oncogene, serine/threonine kinase. 


\begin{tabular}{|c|c|c|c|c|c|c|c|c|}
\hline \multirow[b]{2}{*}{ Study } & \multicolumn{7}{|c|}{ CTC EGFR group } & \multirow[b]{2}{*}{ Specificity $(95 \% \mathrm{Cl})$} \\
\hline & TP & FP & $\mathrm{FN}$ & TN & Sensitivity $(95 \% \mathrm{Cl})$ & Specificity $(95 \% \mathrm{Cl})$ & Sensitivity $(95 \% \mathrm{Cl})$ & \\
\hline Breitenbuecher F 2014 & 8 & 0 & 0 & 0 & $1.00(0.63-1.00)$ & Not estimable & $\longrightarrow$ & \\
\hline He J 2017 & 74 & 0 & 32 & 14 & $0.70(0.60-0.78)$ & $1.00(0.77-1.00)$ & $\rightarrow-$ & \\
\hline Maheswaran S 2008 & 13 & 6 & 1 & 3 & $0.93(0.66-1.00)$ & $0.33(0.07-0.70)$ & - & $=$ \\
\hline Marchetti A 2014 & 31 & 0 & 6 & 0 & $0.84(0.68-0.94)$ & Not estimable & $\rightarrow-$ & \\
\hline Punnoose EA 2012 & 1 & 0 & 1 & 27 & $0.50(0.01-0.99)$ & $1.00(0.87-1.00)$ & $1-$ & - \\
\hline
\end{tabular}

\begin{tabular}{|c|c|c|c|c|c|c|c|c|}
\hline \multicolumn{9}{|c|}{ CTC KRAS group } \\
\hline Study & TP & FP & FN & TN & Sensitivity $(95 \% \mathrm{Cl})$ & Specificity $(95 \%$ & I) Sensitivity $(95 \% \mathrm{Cl})$ & Specificity $(95 \% \mathrm{Cl})$ \\
\hline Freidin MB 2015 & 12 & 7 & 11 & 52 & $0.52(0.31-0.73)$ & $0.88(0.77-0.95)$ & $\longrightarrow$ & $\rightarrow$ \\
\hline Guibert N 2016 & 11 & 0 & 21 & 0 & $0.34(0.19-0.53)$ & Not estimable & $\longrightarrow$ & \\
\hline Punnoose EA 2012 & 0 & 0 & 5 & 40 & $0(0-0.52)$ & $1.00(0.91-1.00)$ & +1 & \\
\hline & & & & & & & $\begin{array}{lllll}0 & 0.2 & 0.4 & 0.6 & 0.8\end{array}$ & $\begin{array}{llll}0.2 & 0.4 & 0.6 & 0.8\end{array}$ \\
\hline
\end{tabular}

Figure 4 Summary plots of sensitivity and specificity of the CTC group.

Abbreviations: CTC, circulating tumor cell; EGFR, epidermal growth factor receptor; TP, true positive; FP, false positive; TN, true negative; FN, false negative; KRAS, kirsten rat sarcoma viral oncogene homolog.

ctDNA had low sensitivity, contrary to the results of the following two studies. ${ }^{63,64}$ Guibert et al analyzed only six samples, and did not regard tissue biopsy as the reference standard.$^{63}$ Different sample size and reference standard were considered as the reasons for the discrepancy. Thierry et $\mathrm{al}^{64}$ concentrated on the value of ctDNA in colorectal cancer. Different $B R A F$ mutational load between lung cancer and colorectal cancer may have led to the difference in results.
CTCs and ctDNA showed great variance in performance for different gene mutations and different detection kits, and methods may have contributed also.

\section{Subgroup analyses}

In view of individual treatment, analyzing detailed $E G F R$ mutation subtypes is critical. Therefore, we focused on the value of CTCs and ctDNA in testing detailed EGFR-mutation

ctDNA EGFR group

\begin{tabular}{|c|c|c|c|c|c|c|c|c|}
\hline Study & TP & FP & FN & TN & Sensitivity $(95 \% \mathrm{CI})$ & Specificity $(95 \% \mathrm{CI})$ & Sensitivity $(95 \% \mathrm{CI})$ & Specificity $(95 \% \mathrm{Cl})$ \\
\hline Arriola E 2018 & 10 & 4 & 12 & 117 & $0.45(0.24-0.68)$ & $0.97(0.92-0.99)$ & & \\
\hline Chai X 2016 & 23 & 8 & 9 & 21 & $0.72(0.53-0.86)$ & $0.72(0.53-0.87)$ & & - \\
\hline Douillard JY 2014 & 69 & 1 & 36 & 546 & $0.66(0.56-0.75)$ & $1.00(0.99-1.00)$ & & \\
\hline Gu J 2017 & 23 & 4 & 5 & 79 & $0.82(0.63-0.94)$ & $0.95(0.88-0.99)$ & & \\
\hline Guo ZW 2017 & 8 & 0 & 4 & 8 & $0.67(0.35-0.90)$ & $1.00(0.63-1.00)$ & & \\
\hline Han JY 2016 & 34 & 18 & 17 & 125 & $0.67(0.52-0.79)$ & $0.87(0.81-0.92)$ & & \\
\hline He C 2009 & 8 & 1 & 0 & 9 & $1.00(0.63-1.00)$ & $0.90(0.55-1.00)$ & & \\
\hline He J 2016 & 187 & 0 & 13 & 0 & $0.94(0.89-0.96)$ & Not estimable & & \\
\hline He J 2017 & 83 & 0 & 23 & 14 & $0.78(0.69-0.86)$ & $1.00(0.77-1.00)$ & & \\
\hline Ma M 2017 & 47 & 3 & 34 & 73 & $0.58(0.47-0.69)$ & $0.96(0.89-0.99)$ & & \\
\hline Mao X 2017 & 15 & 2 & 3 & 20 & $0.83(0.59-0.96)$ & $0.91(0.71-0.99)$ & & \\
\hline Newman AM 2016 & 22 & 0 & 2 & 33 & $0.92(0.73-0.99)$ & $1.00(0.89-1.00)$ & & \\
\hline Pasquale R 2015 & 16 & 0 & 10 & 70 & $0.62(0.41-0.80)$ & $1.00(0.95-1.00)$ & & \\
\hline Pecuchet N 2016 & 28 & 0 & 19 & 62 & $0.60(0.44-0.74)$ & $1.00(0.94-1.00)$ & & \\
\hline Punnoose EA 2012 & 4 & 0 & 0 & 14 & $1.00(0.40-1.00)$ & $1.00(0.77-1.00)$ & & \\
\hline Rachiglio AM 2016 & 17 & 2 & 5 & 20 & $0.77(0.55-0.92)$ & $0.91(0.71-0.99)$ & & \\
\hline Reck M 2016 & 87 & 25 & 102 & 948 & $0.46(0.39-0.53)$ & $0.97(0.96-0.98)$ & & \\
\hline Schwaederle MC 2017 & 7 & 2 & 6 & 19 & $0.54(0.25-0.81)$ & $0.90(0.70-0.99)$ & & \\
\hline Sun H 2014 & 6 & 0 & 3 & 34 & $0.67(0.30-0.93)$ & $1.00(0.90-1.00)$ & & \\
\hline Thompson JC 2016 & 19 & 0 & 5 & 26 & $0.79(0.58-0.93)$ & $1.00(0.87-1.00)$ & & \\
\hline Uchida J 2015 & 56 & 22 & 47 & 163 & $0.54(0.44-0.64)$ & $0.88(0.83-0.92)$ & & \\
\hline Veldore VH 2018 & 41 & 0 & 4 & 87 & $0.91(0.79-0.98)$ & $1.00(0.96-1.00)$ & & \\
\hline Wang W 2017 & 6 & 2 & 3 & 5 & $0.67(0.30-0.93)$ & $0.71(0.29-0.96)$ & & \\
\hline Wang X 2017 & 49 & 0 & 43 & 132 & $0.53(0.43-0.64)$ & $1.00(0.97-1.00)$ & & \\
\hline Wang Y 2017 & 52 & 14 & 51 & 70 & $0.50(0.40-0.60)$ & $0.83(0.74-0.91)$ & & \\
\hline Yang X 2016 & 54 & 0 & 19 & 0 & $0.74(0.62-0.84)$ & Not estimable & $t-$ & \\
\hline Yao Y 2017 & 12 & 0 & 5 & 22 & $0.71(0.44-0.90)$ & $1.00(0.85-1.00)$ & - & \\
\hline \multirow[t]{2}{*}{ Zhou Y 2017} & 5 & 1 & 3 & 20 & $0.63(0.24-0.91)$ & $0.95(0.76-1.00)$ & & \\
\hline & & & & & & & $\begin{array}{lllll}0 & 0.2 & 0.4 & 0.6 & 0.8\end{array}$ & $\begin{array}{lllll}0 & 0.2 & 0.4 & 0.6 & 0.8\end{array}$ \\
\hline
\end{tabular}

Figure 5 (Continued) 


\begin{tabular}{|c|c|c|c|c|c|c|c|c|}
\hline \multicolumn{9}{|c|}{ ctDNA KRAS group } \\
\hline Study & TP & FP & FN & TN & Sensitivity $(95 \% \mathrm{CI})$ & Specificity $(95 \% \mathrm{CI})$ & Sensitivity $(95 \% \mathrm{CI})$ & Specificity $(95 \% \mathrm{CI})$ \\
\hline Del RM 2017 & 3 & 2 & 0 & 3 & $1.00(0.29-1.00)$ & $0.60(0.15-0.95)$ & & - \\
\hline Freidin MB 2015 & 22 & 3 & 1 & 56 & $0.96(0.78-1.00)$ & $0.95(0.86-0.99)$ & & $\rightarrow$ \\
\hline Gautschi O 2007 & 4 & 2 & 0 & 3 & $1.00(0.40-1.00)$ & $0.60(0.15-0.95)$ & & - \\
\hline Han JY 2016 & 6 & 13 & 6 & 110 & $0.50(0.21-0.79)$ & $0.89(0.83-0.94)$ & & - 를 \\
\hline Mao X 2017 & 5 & 1 & 0 & 34 & $1.00(0.48-1.00)$ & $0.97(0.85-1.00)$ & & $\rightarrow$ \\
\hline Pecuchet N 2016 & 19 & 0 & 10 & 80 & $0.66(0.46-0.82)$ & $1.00(0.95-1.00)$ & & \\
\hline Punnoose EA 2012 & 3 & 0 & 15 & 0 & $0.17(0.04-0.41)$ & Not estimable & & \\
\hline Thompson JC 2016 & 2 & 0 & 1 & 47 & $0.67(0.09-0.99)$ & $1.00(0.92-1.00)$ & & \\
\hline Wang Z 2017 & 10 & 0 & 7 & 86 & $0.59(0.33-0.82)$ & $1.00(0.96-1.00)$ & & \\
\hline Yao Y 2017 & 3 & 0 & 1 & 35 & $0.75(0.19-0.99)$ & $1.00(0.90-1.00)$ & & \\
\hline & & & & & & & $\begin{array}{lllll}0 & 0.2 & 0.4 & 0.6 & 0.8\end{array}$ & $\begin{array}{llll}0.2 & 0.4 & 0.6 & 0.8\end{array}$ \\
\hline
\end{tabular}

ctDNA BRAF group

\begin{tabular}{|c|c|c|c|c|c|c|c|c|}
\hline Study & TP & FP & FN & TN & Sensitivity $(95 \% \mathrm{Cl})$ & Specificity $(95 \% \mathrm{CI})$ & Sensitivity $(95 \% \mathrm{CI})$ & Specificity $(95 \% \mathrm{Cl})$ \\
\hline Mao X 2017 & 2 & 1 & 0 & 37 & $1.00(0.16-1.00)$ & $0.97(0.86-1.00)$ & 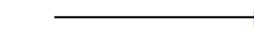 & $\rightarrow$ \\
\hline Pecuchet N 2016 & 2 & 0 & 1 & 106 & $0.67(0.09-0.99)$ & $1.00(0.97-1.00)$ & & \\
\hline Punnoose EA 2012 & 0 & 0 & 15 & 0 & $0.00(0.00-0.22)$ & Not estimable & - & \\
\hline Thompson JC 2016 & 1 & 0 & 0 & 49 & $1.00(0.03-1.00)$ & $1.00(0.93-1.00)$ & & $\rightarrow$ \\
\hline \multirow[t]{2}{*}{ Wang Z 2017} & 2 & 0 & 0 & 101 & $1.00(0.16-1.00)$ & $1.00(0.96-1.00)$ & & \\
\hline & & & & & & & $\begin{array}{lllll}0 & 0.2 & 0.4 & 0.6 & 0.8\end{array}$ & $\begin{array}{llllll}0 & 0.2 & 0.4 & 0.6 & 0.8 & 1\end{array}$ \\
\hline
\end{tabular}

Figure 5 Summary plots of sensitivity and specificity of the ctDNA group.

Abbreviations: CtDNA, circulating tumor DNA; EGFR, epidermal growth factor receptor; TP, true positive; FP, false positive; TN, true negative; FN, false negative; KRAS, kirsten rat sarcoma viral oncogene homolog; BRAF, B-Raf proto-oncogene, serine/threonine kinase.

subtypes. We found that ctDNA had slightly higher accuracy for del19 and L858R. Different-accuracy detection methods may have an impact. More sensitive methods, including droplet digital PCR and circulating single-molecule amplification and resequencing technology, were used in the ctDNA group. For T790M, which is largely responsible for resistance to first-generation or irreversible tyrosine-kinase inhibitors, ${ }^{65}$ CTCs and ctDNA showed similar diagnostic performance. This was consistent with other researchers. ${ }^{14,66}$

Various detection methods had great influence on the accuracy of CTCs and ctDNA; therefore, subgroup analyses based on different detection methods were necessary. In both the CTC and ctDNA groups, sequencing outperformed other detection methods, whether detecting EGFR, KRAS, or $B R A F$. To our knowledge, the low limit of detection and ability to determine lower mutant-allele frequency confers excellent capacity upon sequencing. ${ }^{67,68}$ Although PCR is a cost-effective technology, it can analyze only limited genomic loci and has a high requirement for mutant-allele frequency ${ }^{58}$ Notably, digital PCR, as distinct from traditional PCR, is considered a very sensitive detection method, ${ }^{69,70}$ and our study also confirmed this (data not shown).

\section{Strengths and limitations}

Although several meta-analyses were carried out, they focused on the diagnostic value of ctDNA or CTCs in only one type of gene mutation. ${ }^{59,71,72}$ This is the first comprehensive study to analyze the diagnostic value of both ctDNA and CTCs for various gene mutations in lung cancer. We found that ctDNA might have better diagnostic performance than CTCs; however, clinical application of ctDNA for genemutation detection in lung cancer still needs to consider cost, operation process, and other factors. Meanwhile, subgroup analyses based on detailed EGFR-mutation subtypes, the detection methods of CTCs or ctDNA, and consistency of detection methods between liquid biopsy and tissue biopsy, were also carried out to explore potential influencing factors. However, other gene mutations in lung cancer, such as PIK3CA and TP53, were not included in our study, due to limited literature, which is the subjects of further investigations.

\section{Conclusion}

For lung cancer, ctDNA showed equivalent diagnostic ability as CTCs when detecting EGFR and its subtypes, and excellent performance for $K R A S$ - and $A L K$-mutation detection. In general, ctDNA might be more suitable for clinical application of gene-mutation detection in lung cancer. Furthermore, our study also implies the significance of effective extraction kits and detection methods for improving the diagnostic capacity of ctDNA and CTCs. 
Table 3 Results of subgroup analyses

\begin{tabular}{|c|c|c|c|c|c|c|c|}
\hline & $\mathbf{n}$ & $\chi^{2}$ & $P$-value & Sensitivity $(95 \% \mathrm{Cl})$ & $I^{2}$ & Specificity $(95 \% \mathrm{CI})$ & $I^{2}$ \\
\hline \multicolumn{8}{|l|}{ СТС } \\
\hline \multicolumn{8}{|l|}{ EGFR-mutation types } \\
\hline dell9 subgroup & 3 & 1.00 & $<0.001$ & $75.9 \%(0.654-0.845)$ & $85.2 \%$ & $98.0 \%(0.917-0.999)$ & $66.4 \%$ \\
\hline L858R subgroup & 4 & 6.01 & 0.111 & $62.2 \%(0.50 \mathrm{I}-0.732)$ & 0 & $98.7 \%(0.929-1.000)$ & $45.1 \%$ \\
\hline T790M subgroup & 3 & 2.02 & 0.365 & $63.3 \%(0.353-0.860)$ & $60.8 \%$ & $75.0 \%(0.522-0.908)$ & $57.5 \%$ \\
\hline \multicolumn{8}{|l|}{ Detection methods } \\
\hline EGFR sequencing & 2 & 0.15 & 0.695 & $85.1 \%(0.717-0.938)$ & 0 & $50.0 \%(0.013-0.987)$ & 0 \\
\hline EGFR PCR & 3 & 1.85 & 0.396 & $72.1 \%(0.633-0.799)$ & $56.1 \%$ & $88.0 \%(0.757-0.955)$ & $92.1 \%$ \\
\hline KRAS PCR & 2 & 0.84 & 0.358 & $30.8 \%(0.170-0.476)$ & $50.8 \%$ & $97.6 \%(0.874-0.999)$ & $62.5 \%$ \\
\hline \multicolumn{8}{|l|}{ Consistent or inconsistent } \\
\hline EGFR consistent & 4 & 2.83 & 0.418 & $69.8 \%(0.6 \mathrm{II}-0.775)$ & $41.0 \%$ & $97.7 \%(0.877-0.999)$ & $55.4 \%$ \\
\hline KRAS consistent & 2 & 0 & 0.963 & $42.0 \%(0.227-0.632)$ & $76.6 \%$ & $90.9 \%(0.836-0.956)$ & $84.6 \%$ \\
\hline KRAS inconsistent & 2 & 1.67 & 0.197 & $42.0 \%(0.289-0.559)$ & $40.1 \%$ & $87.5 \%(0.764-0.946)$ & 0 \\
\hline \multicolumn{8}{|l|}{ ctDNA } \\
\hline \multicolumn{8}{|l|}{ EGFR-mutation types } \\
\hline del19 subgroup & 19 & 143.29 & $<0.001$ & $79.0 \%(0.767-0.812)$ & $91.5 \%$ & $95.8 \%(0.948-0.967)$ & $93.1 \%$ \\
\hline L858R subgroup & 20 & 58.54 & $<0.001$ & $76.7 \%(0.73 \mathrm{I}-0.800)$ & $70.2 \%$ & $97.2 \%(0.964-0.979)$ & $70.9 \%$ \\
\hline T790M subgroup & 17 & 31.41 & 0.012 & $61.2 \%(0.570-0.654)$ & $41.3 \%$ & $92.7 \%(0.909-0.943)$ & $86.7 \%$ \\
\hline L86IQ subgroup & 2 & 0.18 & 0.670 & $100 \%(0.292-1.000)$ & 0 & $99.4 \%(0.966-1.000)$ & $50.5 \%$ \\
\hline E20ins subgroup & 3 & 1.53 & 0.467 & $83.3 \%(0.359-0.996)$ & $24.1 \%$ & $98.3 \%(0.964-0.994)$ & $0.6 \%$ \\
\hline G7I9X subgroup & 2 & 0.09 & 0.765 & $100 \%(0.398-1.000)$ & 0 & $97.4 \%(0.935-0.993)$ & $71.5 \%$ \\
\hline S768I subgroup & 2 & 0.27 & 0.606 & $75.0 \%(0.06 \mid-1.000)$ & 0 & $99.5 \%(0.979-1.000)$ & $21.0 \%$ \\
\hline \multicolumn{8}{|l|}{ Detection methods } \\
\hline EGFR sequencing & 10 & 24.13 & 0.004 & $75.6 \%(0.698-0.807)$ & $59.0 \%$ & $95.8 \%(0.93-0.977)$ & $78.5 \%$ \\
\hline EGFR PCR & 15 & 45.27 & $<0.001$ & $67.2 \%(0.643-0.70 \mathrm{I})$ & $91.0 \%$ & $97.2 \%(0.965-0.979)$ & $83.3 \%$ \\
\hline EGFR others & 3 & 6.15 & 0.046 & $54.5 \%(0.469-0.621)$ & $55.7 \%$ & $89.7 \%(0.86-0.926)$ & $83.9 \%$ \\
\hline KRAS sequencing & 6 & 7.37 & 0.195 & $66.9 \%(0.535-0.786)$ & 0 & $97.8 \%(0.954-0.99 \mid)$ & $87.9 \%$ \\
\hline KRAS PCR & 4 & 8.05 & 0.045 & $63.3 \%(0.477-0.772)$ & $91.0 \%$ & $84.5 \%(0.742-0.918)$ & $41.5 \%$ \\
\hline KRAS others & 2 & 8.92 & 0.003 & $80.0 \%(0.63|-0.9| 6)$ & $90.2 \%$ & $91.2 \%(0.86 \mathrm{I}-0.949)$ & $38.8 \%$ \\
\hline BRAF sequencing & 4 & 0.62 & 0.892 & $87.5 \%(0.473-0.997)$ & 0 & $99.7 \%(0.98 \mathrm{I}-1.000)$ & $27.1 \%$ \\
\hline \multicolumn{8}{|l|}{ Consistent or inconsistent } \\
\hline EGFR consistent & 16 & 62.81 & $<0.001$ & $69.3 \%(0.664-0.720)$ & $88.5 \%$ & $95.7 \%(0.945-0.967)$ & $88.2 \%$ \\
\hline EGFR inconsistent & 10 & 23.25 & 0.006 & $74.6 \%(0.682-0.804)$ & $65.4 \%$ & $95.5 \%(0.933-0.972)$ & $78.6 \%$ \\
\hline KRAS consistent & 7 & 15.14 & 0.019 & $62.8 \%(0.519-0.727)$ & $82.5 \%$ & $92.1 \%(0.886-0.949)$ & $79.9 \%$ \\
\hline KRAS inconsistent & 4 & 8.21 & 0.042 & $81.5 \%(0.673-0.914)$ & $73.6 \%$ & $95.0 \%(0.908-0.976)$ & $90.2 \%$ \\
\hline BRAF consistent & 2 & 10.06 & 0.002 & $13.2 \%(0.023-0.364)$ & $84.7 \%$ & $99.5 \%(0.957-1.000)$ & $79.9 \%$ \\
\hline$B R A F$ inconsistent subgroup & 2 & 0.62 & 0.431 & $100 \%(0.398-1.000)$ & 0 & $99.3 \%(0.961-1.000)$ & $61.7 \%$ \\
\hline
\end{tabular}

Abbreviations: CTC, circulating tumor cell; CtDNA, circulating tumor DNA.

\section{Availability of data and material}

All data generated or analyzed during this study are included in this published article.

\section{Acknowledgments}

We are grateful to Hong Xie for her advice on English language editing of this manuscript. This work was supported by the National Natural Science Foundation of China (grants 81472026 and 81672095).

\section{Author contributions}

All authors contributed to data analysis, drafting and revising the article, gave final approval of the version to be published, and agree to be accountable for all aspects of the work.

\section{Disclosure}

The authors report no conflicts of interest in this work. 


\section{References}

1. Bray F, Ferlay J, Soerjomataram I, Siegel RL, Torre LA, Jemal A. Global cancer statistics 2018: GLOBOCAN estimates of incidence and mortality worldwide for 36 cancers in 185 countries. $C A$ Cancer J Clin. 2018;68(6):394-424. doi: 10.3322/caac.21492

2. Mraihi Z, Ben Amar J, Bouacha H, Rammeh S, Hila L. EGFR mutation status in Tunisian non-small-cell lung cancer patients evaluated by mutation-specific immunohistochemistry. BMC Pulm Med. 2018; 18(1):132. doi: 10.1186/s12890-018-0706-5

3. Yoneda K, Imanishi N, Ichiki Y, Tanaka F. A liquid biopsy in primary lung cancer. Surg Today. 2018;49(1):1-14.

4. Lu J, Han B. Liquid biopsy promotes non-small cell lung cancer precision therapy. Technol Cancer Res Treat. 2018;17:1533033818801809. doi: $10.1177 / 1533033818801809$

5. Cheng F, Su L, Qian C. Circulating tumor DNA: a promising biomarker in the liquid biopsy of cancer. Oncotarget. 2016;7(30):48832-48841. doi: 10.18632/oncotarget.9453

6. Zhang J, Chen K, Fan Z. Circulating tumor cell isolation and analysis. Adv Clin Chem. 2016;75:1-31. doi: 10.1016/bs.acc.2016.03.003

7. Kidess E, Jeffrey SS. Circulating tumor cells versus tumor-derived cell-free DNA: rivals or partners in cancer care in the era of single-cell analysis? Genome Med. 2013;5(8):70.

8. Whiting PF, Rutjes AW, Westwood ME, et al; QUADAS-2 Group. QUADAS-2: a revised tool for the quality assessment of diagnostic accuracy studies. Ann Intern Med. 2011;155(8):529-536.

9. Higgins JPTG. Cochrane handbook for systematic reviews of interventions version 5.1.0. The Cochrane Collaboration. 2011 [updated March 2011]. Available from: www.cochrane-handbook.org. Accessed January 2, 2018.

10. Breitenbuecher F, Hoffarth S, Worm K, et al. Development of a highly sensitive and specific method for detection of circulating tumor cells harboring somatic mutations in non-small-cell lung cancer patients. PLoS One. 2014;9(1):e85350. doi: 10.1371/journal.pone.0085350

11. Freidin MB, Freydina DV, Leung M, Montero Fernandez A, Nicholson AG, Lim E. Circulating tumor DNA outperforms circulating tumor cells for KRAS mutation detection in thoracic malignancies. Clin Chem. 2015;61(10):1299-1304. doi: 10.1373/clinchem.2015.242453

12. Guibert N, Pradines A, Farella M, et al. Monitoring KRAS mutations in circulating DNA and tumor cells using digital droplet PCR during treatment of KRAS-mutated lung adenocarcinoma. Lung Cancer. 2016;100: 1-4. doi: 10.1016/j.lungcan.2016.07.021

13. He J, Tan W, Tang X, Ma J. Variations in EGFR ctDNA correlates to the clinical efficacy of afatinib in non small cell lung cancer with acquired resistance. Pathol Oncol Res. 2017;23(2):307-315. doi: 10.1007/s12253016-0097-y

14. Maheswaran S, Sequist LV, Nagrath S, et al. Detection of mutations in EGFR in circulating lung-cancer cells. $N$ Engl J Med. 2008;359(4): 366-377. doi: 10.1056/NEJMoa0800668

15. Marchetti A, Del Grammastro M, Felicioni L, et al. Assessment of EGFR mutations in circulating tumor cell preparations from NSCLC patients by next generation sequencing: toward a real-time liquid biopsy for treatment. PLoS One. 2014;9(8):e103883. doi: 10.1371/journal.pone.0103883

16. Punnoose EA, Atwal S, Liu W, et al. Evaluation of circulating tumor cells and circulating tumor DNA in non-small cell lung cancer: association with clinical endpoints in a phase II clinical trial of pertuzumab and erlotinib. Clin Cancer Res. 2012;18(8):2391-2401. doi: 10.1158/10780432.CCR-11-3148

17. Sundaresan TK, Sequist LV, Heymach JV, et al. Detection of T790M, the acquired resistance EGFR mutation, by tumor biopsy versus noninvasive blood-based analyses. Clin Cancer Res. 2016;22(5):1103-1110. doi: 10.1158/1078-0432.CCR-15-1031

18. Yeo T, Tan SJ, Lim CL, et al. Microfluidic enrichment for the single cell analysis of circulating tumor cells. Sci Rep. 2016;6:22076.

19. Arriola E, Paredes-Lario A, Garcia-Gomez R, et al. Comparison of plasma ctDNA and tissue/cytology-based techniques for the detection of EGFR mutation status in advanced NSCLC: Spanish data subset from ASSESS. Clin Transl Oncol. 2018;20(10):1261-1267. doi: 10.1007/ s12094-018-1855-y
20. Chai X, Ren P, Wei B, et al. A comparative study of EGFR oncogenic mutations in matching tissue and plasma samples from patients with advanced non-small cell lung carcinoma. Clin Chim Acta. 2016;457:106-111.

21. Del Re M, Tiseo M, Bordi P, et al. Contribution of KRAS mutations and c.2369C > T (p.T790M) EGFR to acquired resistance to EGFRTKIs in EGFR mutant NSCLC: a study on circulating tumor DNA. Oncotarget. 2017;8(8):13611-13619. doi: 10.18632/oncotarget.6957

22. Douillard JY, Ostoros G, Cobo M, et al. Gefitinib treatment in EGFR mutated caucasian NSCLC: circulating-free tumor DNA as a surrogate for determination of EGFR status. J Thorac Oncol. 2014;9(9): 1345-1353. doi: 10.1097/JTO.0000000000000263

23. Gautschi O, Huegli B, Ziegler A, et al. Origin and prognostic value of circulating KRAS mutations in lung cancer patients. Cancer Lett. 2007;254(2):265-273.

24. Gu J, Zang W, Liu B, et al. Evaluation of digital PCR for detecting low-level EGFR mutations in advanced lung adenocarcinoma patients: a cross-platform comparison study. Oncotarget. 2017;8(40): 67810-67820. doi: 10.18632/oncotarget.18866

25. Guo ZW, Li M, Li JQ, et al. Circulating tumor DNA detection in advanced non-small cell lung cancer patients. Transl Cancer Res. 2017;6(5): 878-885. doi: $10.21037 /$ tcr.2017.08.03

26. Han JY, Choi JJ, Kim JY, Han YL, Lee GK. PNA clamping-assisted fluorescence melting curve analysis for detecting EGFR and KRAS mutations in the circulating tumor DNA of patients with advanced non-small cell lung cancer. BMC Cancer. 2016;16:627. doi: 10.1186/ s12885-016-2678-2

27. He C, Liu M, Zhou C, et al. Detection of epidermal growth factor receptor mutations in plasma by mutant-enriched PCR assay for prediction of the response to gefitinib in patients with non-small-celi lung cancer. Int J Cancer. 2009;125(10):2393-2399. doi: 10.1002/ijc.24653

28. He J, Tan W, Ma J. Circulating tumor cells and DNA for real-time EGFR detection and monitoring of non-small-cell lung cancer. Future Oncol. 2017;13(9):787-797. doi: 10.2217/fon-2016-0427

29. Jenkins S, Yang JC, Ramalingam SS, et al. Plasma ctDNA analysis for detection of the EGFR T790M mutation in patients with advanced non-small cell lung cancer. J Thorac Oncol. 2017;12(7):1061-1070. doi: $10.1016 /$ j.jtho.2017.04.003

30. Kim CG, Shim HS, Hong MH, et al. Detection of activating and acquired resistant mutation in plasma from EGFR-mutated NSCLC patients by peptide nucleic acid (PNA) clamping-assisted fluorescence melting curve analysis. Oncotarget. 2017;8(39):65111-65122. doi: 10.18632/ oncotarget.17786

31. Kobayashi K, Naoki K, Manabe T, et al. Comparison of detection methods of EGFR T790M mutations using plasma, serum, and tumor tissue in EGFR-TKI-resistant non-small cell lung cancer. Onco Targets Ther. 2018;11:3335-3343. doi: 10.2147/OTT.S161745

32. Lee Y, Park S, Kim WS, et al. Correlation between progression-free survival, tumor burden, and circulating tumor DNA in the initial diagnosis of advanced-stage EGFR-mutated non-small cell lung cancer. Thorac Cancer. 2018;9(9):1104-1110. doi: 10.1111/1759-7714.12793

33. Ma M, Shi C, Qian J, Han B. Accuracy and clinical influence of plasma EGFR mutation detection in management of advanced lung adenocarcinoma. Int J Clin Exp Pathol. 2017;10(9):9559-9566.

34. Ma M, Shi C, Qian J, Teng J, Zhong H, Han B. Comparison of plasma and tissue samples in epidermal growth factor receptor mutation by ARMS in advanced non-small cell lung cancer. Gene. 2016;591(1): 58-64. doi: 10.1016/j.gene.2016.06.053

35. Newman AM, Lovejoy AF, Klass DM, et al. Integrated digital error suppression for improved detection of circulating tumor DNA. Nat Biotechnol. 2016;34(5):547-555. doi: 10.1038/nbt.3520

36. Pasquale R, Fenizia F, Esposito Abate R, et al. Assessment of highsensitive methods for the detection of EGFR mutations in circulating free tumor DNA from NSCLC patients. Pharmacogenomics. 2015; 16(10):1135-1148. doi: 10.2217/pgs.15.45

37. Pecuchet N, Zonta E, Didelot A, et al. Base-position error rate analysis of next-generation sequencing applied to circulating tumor DNA in non-small cell lung cancer: a prospective study. PLoS Med. 2016;13(12):e1002199. doi: 10.1371/journal.pmed.1002199 
38. Rachiglio AM, Abate RE, Sacco A, et al. Limits and potential of targeted sequencing analysis of liquid biopsy in patients with lung and colon carcinoma. Oncotarget. 2016;7(41):66595-66605. doi: 10.18632/ oncotarget.10704

39. Reck M, Hagiwara K, Han B, et al. ctDNA determination of EGFR mutation status in European and Japanese patients with advanced NSCLC: the ASSESS study. J Thorac Oncol. 2016;11(10):1682-1689. doi: $10.1016 /$ j.jtho.2016.05.036

40. Schwaederle MC, Patel SP, Husain H, et al. Utility of genomic assessment of blood-derived circulating tumor DNA (ctDNA) in patients with advanced lung adenocarcinoma. Clin Cancer Res. 2017;23(17): 5101-5111. doi: 10.1158/1078-0432.CCR-16-2497

41. Sun H, Gan ZC, Gao JJ, Zheng F. Non-invasive detection of EGFR deletion at exon 19 in non-small cell lung cancer by real time diagnostic. Clin Lab. 2014;60(9):1517-1526.

42. Thompson JC, Yee SS, Troxel AB, et al. Detection of therapeutically targetable driver and resistance mutations in lung cancer patients by next-generation sequencing of cell-free circulating tumor DNA Clin Cancer Res. 2016;22(23):5772-5782. doi: 10.1158/1078-0432. CCR-16-1231

43. Thress KS, Brant R, Carr TH, et al. EGFR mutation detection in ctDNA from NSCLC patient plasma: a cross-platform comparison of leading technologies to support the clinical development of AZD9291. Lung Cancer. 2015;90(3):509-515. doi: 10.1016/j.lungcan.2015. 10.004

44. Uchida J, Kato K, Kukita Y, et al. Diagnostic accuracy of noninvasive genotyping of EGFR in lung cancer patients by deep sequencing of plasma cell-free DNA. Clin Chem. 2015;61(9):1191-1196. doi: 10.1373/clinchem.2015.241414

45. Veldore VH, Choughule A, Routhu T, et al. Validation of liquid biopsy: plasma cell-free DNA testing in clinical management of advanced non-small cell lung cancer. Lung Cancer (Auckl). 2018;9:1-11. doi: 10.2147/LCTT.S147841

46. Wang W, Song Z, Zhang Y. A comparison of ddPCR and ARMS for detecting EGFR T790M status in ctDNA from advanced NSCLC patients with acquired EGFR-TKI resistance. Cancer Med. 2017;6(1): 154-162. doi: 10.1002/cam4.978

47. Wang X, Gao Y, Wang B, et al. Analytic and clinical validation of an ultrasensitive, quantitative polymerase chain reaction assay for EGFR mutation analysis with circulating tumor DNA. Arch Pathol Lab Med. 2017;141(7):978-984. doi: 10.5858/arpa.2016-0083-OA

48. Wang Y, Duan J, Chen H, et al. Analysis of EGFR mutation status in tissue and plasma for predicting response to EGFR-TKIs in advanced non-small-cell lung cancer. Oncol Lett. 2017;13(4):2425-2431. doi: 10.3892/ol.2017.5740

49. Wang Z, Cheng G, Han X, et al. Application of single-molecule amplification and resequencing technology for broad surveillance of plasma mutations in patients with advanced lung adenocarcinoma. J Mol Diagn. 2017;19(1):169-181. doi: 10.1016/j.jmoldx.2016.09.008

50. Wu YL, Tong RZ, Zhang Y, et al. Conventional real-time PCR-based detection of T790M using tumor tissue or blood in patients with EGFR TKI-resistant NSCLC. Onco Targets Ther. 2017;10:3307-3312. doi: 10.2147/OTT.S136823

51. Xu F, Wu J, Xue C, et al. Comparison of different methods for detecting epidermal growth factor receptor mutations in peripheral blood and tumor tissue of non-small cell lung cancer as a predictor of response to gefitinib. Onco Targets Ther. 2012;5:439-447. doi: 10.2147/OTT. S37289

52. Yang X, Zhuo M, Ye X, et al. Quantification of mutant alleles in circulating tumor DNA can predict survival in lung cancer. Oncotarget. 2016;7(15):20810-20824. doi: 10.18632/oncotarget.8021

53. Yao Y, Liu J, Li L, et al. Detection of circulating tumor DNA in patients with advanced non-small cell lung cancer. Oncotarget. 2017;8(2): 2130-2140. doi: 10.18632/oncotarget.12883

54. Yoshida H, Kim YH, Ozasa H, et al. EGFR T790M detection in circulating tumor DNA from non-small cell lung cancer patients using the PNA-LNA clamp method. Anticancer Res. 2017;37(5):2721-2725. doi: 10.21873/anticanres.11623
55. Zheng D, Ye X, Zhang MZ, et al. Plasma EGFR T790M ctDNA status is associated with clinical outcome in advanced NSCLC patients with acquired EGFR-TKI resistance. Sci Rep. 2016;6:20913. doi: 10.1038/ srep20913

56. Zhou Y, Yang Y, Yang C, et al. Epidermal growth factor receptor (EGFR) mutations in non-small cell lung cancer (NSCLC) of Yunnan in southwestern China. Oncotarget. 2017;8(9):15023-15033. doi: 10.18632/oncotarget.14706

57. Lin CC, Huang WL, Wei F, Su WC, Wong DT. Emerging platforms using liquid biopsy to detect EGFR mutations in lung cancer. Expert Rev Mol Diagn. 2015;15(11):1427-1440. doi: 10.1586/14737159.2015.1094379

58. Gorgannezhad L, Umer M, Islam MN, Nguyen NT, Shiddiky MJA. Circulating tumor DNA and liquid biopsy: opportunities, challenges, and recent advances in detection technologies. Lab Chip. 2018;18(8) 1174-1196. doi: 10.1039/C8LC00100F

59. Shen H, Che K, Cong L, et al. Diagnostic and prognostic value of blood samples for KRAS mutation identification in lung cancer: a meta-analysis. Oncotarget. 2017;8(22):36812-36823. doi: 10.18632/ oncotarget.15972

60. Chong IW, Chang MY, Sheu CC, et al. Detection of activated K-ras in non-small cell lung cancer by membrane array: a comparison with direct sequencing. Oncol Rep. 2007;18(1):17-24.

61. Tsao DA, Yang MJ, Chang HJ, et al. A fast and convenient new technique to detect the therapeutic target, K-ras mutant, from peripheral blood in non-small cell lung cancer patients. Lung Cancer. 2010; 68(1):51-57.

62. McCoach CE, Blakely CM, Banks KC, et al. Clinical utility of cell-free DNA for the detection of ALK fusions and genomic mechanisms of ALK inhibitor resistance in non-small cell lung cancer. Clin Cancer Res. 2018;24(12):2758-2770.

63. Guibert N, Pradines A, Casanova A, et al. Detection and monitoring of the BRAF mutation in circulating tumor cells and circulating tumor DNA in BRAF-mutated lung adenocarcinoma. J Thorac Oncol. 2016; 11(9):e109-e112.

64. Thierry AR, Mouliere F, El Messaoudi S, et al. Clinical validation of the detection of KRAS and BRAF mutations from circulating tumor DNA. Nat Med. 2014;20(4):430-435.

65. Hidaka N, Iwama E, Kubo N, et al. Most T790M mutations are present on the same EGFR allele as activating mutations in patients with non-small cell lung cancer. Lung Cancer. 2017;108:75-82.

66. Kuang Y, Rogers A, Yeap BY, et al. Noninvasive detection of EGFR T790M in gefitinib or erlotinib resistant non-small cell lung cancer. Clin Cancer Res. 2009;15(8):2630-2636.

67. Murtaza M, Dawson SJ, Tsui DW, et al. Non-invasive analysis of acquired resistance to cancer therapy by sequencing of plasma DNA. Nature. 2013;497(7447):108-112.

68. Harris FR, Kovtun IV, Smadbeck J, et al. Quantification of somatic chromosomal rearrangements in circulating cell-free DNA from ovarian cancers. Sci Rep. 2016;6:29831.

69. Olmedillas Lopez S, Garcia-Olmo DC, Garcia-Arranz M, Guadalajara H, Pastor C, Garcia-Olmo D. KRAS G12V mutation detection by droplet digital PCR in circulating cell-free DNA of colorectal cancer patients. Int J Mol Sci. 2016;17(4):484.

70. Do H, Cameron D, Molania R, et al. Digital PCR of genomic rearrangements for monitoring circulating tumour DNA. Adv Exp Med Biol. 2016;924:139-146.

71. Chougule A, Basak S. Epidermal growth factor receptor T790M testing in progressed lung cancer: a review of sensitive methods for analysis of tissue and liquid biopsy samples. Indian J Cancer. 2017;54(Supplement):S45-S54.

72. Yuan JQ, Zhang YL, Li HT, Mao C. EGFR mutation testing in blood for guiding EGFR tyrosine kinase inhibitor treatment in patients with nonsmall cell lung cancer A protocol for systematic review and metaanalysis. Medicine (Baltimore). 2017;96(7) 


\section{Publish your work in this journal}

OncoTargets and Therapy is an international, peer-reviewed, open access journal focusing on the pathological basis of all cancers, potential targets for therapy and treatment protocols employed to improve the management of cancer patients. The journal also focuses on the impact of management programs and new therapeutic agents and protocols on

patient perspectives such as quality of life, adherence and satisfaction. The manuscript management system is completely online and includes a very quick and fair peer-review system, which is all easy to use. Visit http://www.dovepress.com/testimonials.php to read real quotes from published authors.

Submit your manuscript here: http://www.dovepress.com/oncotargets-and-therapy-journal 